\title{
BMJ Open Obesity prevalence among healthcare professionals in England: a cross- sectional study using the Health Survey for England
}

Richard G Kyle, ${ }^{1}$ Jane Wills, ${ }^{2}$ Catherine Mahoney, ${ }^{1}$ Louise Hoyle, ${ }^{1}$ Muireann Kelly, ${ }^{2}$ lain M Atherton ${ }^{1}$

To cite: Kyle RG, Wills J, Mahoney C, et al. Obesity prevalence among healthcare professionals in England: a cross-sectional study using the Health Survey for England. BMJ Open 2017;7:e018498. doi:10.1136/ bmjopen-2017-018498

- Prepublication history for this paper is available online. To view these files, please visit the journal online (http://dx.doi org/10.1136/bmjopen-2017018498).

Received 4 July 2017 Revised 14 August 2017 Accepted 20 September 2017

CrossMark

${ }^{1}$ School of Health \& Social Care, Edinburgh Napier University, Edinburgh, UK

${ }^{2}$ School of Health \& Social Care, London South Bank University, London, UK

Correspondence to

Dr Richard G Kyle;

r.kyle@napier.ac.uk

\section{ABSTRACT}

Objective To estimate obesity prevalence among healthcare professionals in England and compare prevalence with those working outside of the health services.

Design Cross-sectional study based on data from 5 years (2008-2012) of the nationally representative Health Survey for England.

Setting England.

Participants 20103 adults aged 17-65 years indicating they were economically active at the time of survey classified into four occupational groups: nurses $(n=422)$, other healthcare professionals $(n=412)$, unregistered care workers $(n=736)$ and individuals employed in nonhealth-related occupations $(n=18533)$.

Outcome measure Prevalence of obesity defined as body mass index $\geq 30.0$ with $95 \%$ Cls and weighted to reflect the population.

Results Obesity prevalence was high across all occupational groups including: among nurses $(25.1 \%$, $95 \% \mathrm{Cl} 20.9 \%$ to $29.4 \%$ ); other healthcare professionals (14.4\%,95\% Cl $11.0 \%$ to $17.8 \%)$; non-health-related occupations (23.5\%, $95 \% \mathrm{Cl} 22.9 \%$ to $24.1 \%)$; and unregistered care workers who had the highest prevalence of obesity (31.9\%, $95 \% \mathrm{Cl} 28.4 \%$ to $35.3 \%)$. A logistic regression model adjusted for sociodemographic composition and survey year indicated that, compared with nurses, the odds of being obese were significantly lower for other healthcare professionals (adjusted OR (aOR) $0.52,95 \% \mathrm{Cl} 0.37$ to 0.75 ) and higher for unregistered care workers (aOR 1.46, 95\% Cl 1.11 to 1.93). There was no significant difference in obesity prevalence between nurses and people working in non-health-related occupations (aOR $0.94,95 \% \mathrm{Cl} 0.74$ to 1.18 ).

Conclusions High obesity prevalence among nurses and unregistered care workers is concerning as it increases the risks of musculoskeletal conditions and mental health conditions that are the main causes of sickness absence in health services. Further research is required to better understand the reasons for high obesity prevalence among healthcare professionals in England to inform interventions to support individuals to achieve and maintain a healthy weight.

\section{INTRODUCTION}

Obesity is linked to increased risk of developing a range of life-limiting illnesses,
Strengths and limitations of this study

- This is the first study to provide reliable estimates of the prevalence of obesity among healthcare professionals in England.

- Data were drawn from a nationally representative sample of the English population, which enables generalisability.

- Height and weight measurements used to derive body mass index were taken by trained interviewers rather than self-reported, which increases reliability.

- Findings establish evidence to support urgent action from National Health Service England to address high rates of obesity among nurses and the unregistered healthcare workforce.

- Heterogeneity of roles and fields of practice within the nursing workforce is masked by the inability to differentiate within the single occupational classification of nurses.

including heart disease, ${ }^{1}$ cancer $^{2}$ and type 2 diabetes. ${ }^{3}$ It is known to increase the likelihood of lower back injury ${ }^{4}$ and has been associated with reduced quality of life. ${ }^{5}$ The WHO has estimated that between $2 \%$ and $7 \%$ of healthcare spending in developed economies can be attributed to obesity. ${ }^{6}$ In the UK, government spending on the direct medical costs of obesity is currently $£ 6$ billion, equivalent to $5 \%$ of the National Health Service (NHS) budget and is estimated to double by $2030 .{ }^{6}$

Prevalence of obesity in the UK ranks third highest in Western Europe after Malta and Iceland with a quarter of UK adults being obese. ${ }^{7}$ In England, $27 \%$ of both men and women are obese, ${ }^{8}$ and $60 \%$ of men and $50 \%$ of women are predicted to be obese by $2050 .^{9}$ Prevalence of obesity among healthcare professionals in England is not known, although the Department of Health in England has estimated that 300000 healthcare professionals can be 
classified as obese $(21 \%),{ }^{10}$ and these figures are likely to have risen in line with population trends. A study in Scotland found that $29 \%$ of nurses, $17 \%$ of other healthcare professionals (including doctors, pharmacists, dentists and therapy professionals) and $35 \%$ of unregistered care workers were obese. ${ }^{11}$ Several studies of the health of healthcare professionals have found that a significant proportion are obese, ${ }^{12-14}$ and a study of nearly 5000 nurses and midwives registered in Australia, New Zealand or the UK found that nurses and midwives have higher prevalence of obesity and overweight than the general population. ${ }^{15}$

It is important to be able to have an accurate assessment of the prevalence of obesity among healthcare professionals for three main reasons. First, obesity increases the likelihood of musculoskeletal disorders ${ }^{16}$ and mental health conditions, ${ }^{17} 18$ which are the leading causes of work-related illness and workplace injury for healthcare professionals. ${ }^{19}$ As well as being implicated in the onset of chronic diseases, these conditions and their associated sickness absence rates pose a potential problem for the efficacy and sustainability of the healthcare system by potentially reducing the capacity of the healthcare workforce.

Second, comparing obesity rates in different healthcare professional groups and with the general population will help to identify the possible contribution of adverse workplace factors such as a lack of access to healthy food options, ${ }^{20}$ shift working ${ }^{21-23}$ and a possible link between obesity and high demand/low control work $^{24} 25$ to increasing obesity among healthcare professionals. $^{24}$

Third, widespread obesity among the workforce may hamper the efficacy of healthcare professionals' health promotion efforts. As the largest professional group within healthcare systems both in the UK and internationally, ${ }^{26}{ }^{27}$ nurses, in particular, have been encouraged to seize 'teachable moments' during routine care to educate and encourage patients to make positive changes to their behaviour. ${ }^{28}$ The NHS Standard Contract ${ }^{29}$ (p. 12) states that 'staff use every contact that they have with Service Users and the public as an opportunity to maintain or improve health and wellbeing'. Indeed, a recent survey of attitudes towards obesity in the UK reported that $60 \%$ of people believed that healthcare professionals were responsible for reducing obesity, second only to individuals who are obese themselves. ${ }^{30}$ Role modelling healthy behaviours is seen as a reasonable professional expectation of nurses. ${ }^{31}$ A systematic review of the impact of personal health behaviours on health promotion practice found that patients are more likely to accept advice offered by a visibly healthy healthcare professional compared with a healthcare professional who is overweight or obese, ${ }^{32}$ and there is evidence that healthcare professionals' lifestyle behaviours influence the frequency and willingness with which they offer health advice. ${ }^{33} 34$

The aim of this study was to estimate the prevalence of obesity among nurses and healthcare professionals in England and compare prevalence with the general working population.

\section{METHODS}

\section{Study design and participants}

Analysis was conducted using the Health Survey for England (HSE), an annual nationally representative sample of the English population. The HSE is a stratified random probability sample of private households in England and is used to estimate prevalence of health conditions and disease risk factors, as well as to plan health services and monitor government performance against policy targets. Data collection from adults over the age of 16 years is conducted using Computer-Assisted Personal Interviewing by an interviewer in participants' homes. Anthropometric measurements, including height and weight, were taken by a trained interviewer, and the methods for collection are published elsewhere. ${ }^{35}$

Five annual rounds of the HSE (2008-2012) were aggregated to ensure sufficient power to enable analysis. To increase comparability between occupational groups, analysis was restricted to participants aged $17-65$ years old and who indicated they were economically active at the time of survey.

\section{Measures}

The four measures of obesity, occupation, gender and age were identified from the HSE. Each measure is discussed in turn.

\section{Obesity}

Interviewers measured participants' height and weight from which body mass index (BMI) was derived. WHO classifications were used in analysis: 'underweight' (BMI <18.5), 'normal' (BMI=18.5-24.9), 'overweight' $(B M I=25.0-29.9)$ and 'obese' (BMI $\geq 30)$. Due to small numbers of underweight participants in the sample, underweight and normal weight categories were aggregated into a single category for analysis.

\section{Occupation}

Survey participants were asked their occupation with responses recorded using free text of up to 60 characters. Free-text responses were then classified using the standard occupational classification (SOC2000 for survey years 2008-2011) and SOC2010 (2012) to create a categorical variable.$^{36}$ Occupations were aggregated into four separate groups: nurses, other healthcare professionals unregistered care workers and non-healthcare occupations. Aggregating occupational categories ensured sufficient numbers to enable comparison. The specific codes used to create each of these occupational groups are shown in table 1.

\section{Sociodemographic characteristics}

Data on gender and age were used in analysis to take account of potential compositional differences between occupational groups. Gender was selected as a covariate 
Table 1 SOC2000 and SOC2010 codes for occupational groups

\begin{tabular}{|c|c|c|}
\hline \multirow[b]{2}{*}{ Occupational group } & \multicolumn{2}{|c|}{$\begin{array}{l}\text { Occupational Classification } \\
\text { scheme } \\
\text { (survey year) }\end{array}$} \\
\hline & $\begin{array}{l}\text { SOC2000 } \\
(2008-2011)\end{array}$ & $\begin{array}{l}\text { SOC2010 } \\
(2012)\end{array}$ \\
\hline Nurses & 3211 & 2231 \\
\hline \multicolumn{3}{|l|}{$\begin{array}{l}\text { Other healthcare } \\
\text { professionals }\end{array}$} \\
\hline Medical practitioner & 2211 & 2211 \\
\hline Psychologists & 2212 & 2212 \\
\hline Pharmacists & 2213 & 2213 \\
\hline Ophthalmic opticians & 2214 & 2214 \\
\hline Dental practitioners & 2215 & 2215 \\
\hline Medical radiographers & 3214 & 2217 \\
\hline Podiatrists & 3215 & 2218 \\
\hline Physiotherapists & 3221 & 2221 \\
\hline Occupational therapists & 3222 & 2222 \\
\hline $\begin{array}{l}\text { Speech and language } \\
\text { therapists }\end{array}$ & 3223 & 2223 \\
\hline $\begin{array}{l}\text { Therapy professionals } \\
\text { (NEC) }\end{array}$ & 3229 & 2229 \\
\hline Midwives & 3212 & 2232 \\
\hline \multicolumn{3}{|l|}{ Unregistered care workers } \\
\hline $\begin{array}{l}\text { Nursing auxiliaries and } \\
\text { assistants }\end{array}$ & 6111 & 6141 \\
\hline $\begin{array}{l}\text { Care assistants and home } \\
\text { carers }\end{array}$ & 6115 & $\mathrm{n} / \mathrm{a}$ \\
\hline $\begin{array}{l}\text { Care workers and home } \\
\text { carers }\end{array}$ & $\mathrm{n} / \mathrm{a}$ & 6145 \\
\hline Senior care workers & $\mathrm{n} / \mathrm{a}$ & 6146 \\
\hline \multicolumn{3}{|l|}{ Non-health occupations } \\
\hline All other codes & All other codes & $\begin{array}{l}\text { All other } \\
\text { codes }\end{array}$ \\
\hline
\end{tabular}

NEC, not elsewhere classified.

because there is a considerable gender imbalance in the English nursing workforce towards female registrants. Age was included to account for different age compositions in each of the occupational comparison groups. The age cut-off of 17 years was used as 17 is the earliest point at which student nurses can enter practice. Using occupational categories for comparison will largely have self-adjusted for differences in socioeconomic status.

\section{Statistical methods}

Only participants with complete data were included in analysis as initial analysis identified no statistically significant difference in the likelihood of respondents in occupational groups having missing data relating to BMI $(\mathrm{P}=0.86)$. Prevalence of obesity was calculated for each occupational group with $95 \%$ CI. Logistic regression models were then used to compare the odds of being obese or not obese between nurses and other occupational groups. First, the model was built using occupational group as the only predictor. Second, sociodemographic variables (ie, gender and age) that might explain differences in prevalence between groups were entered into the model. Survey year was also included to take account of any potential temporal effects. Data were analysed using SAS V.9.1.3. Weights supplied by NatCen were applied in analysis. ${ }^{35}$ These weights increase the degree to which estimates are representative of the English population and adjust the sample to reduce bias from individual non-response within households. Results are shown for weighted data.

\section{RESULTS \\ Sample}

After aggregating data across all five survey years, 66283 individuals were included in the initial dataset. Including only those aged 17-65 years who indicated that they were working at the time of the survey and for whom occupation was recorded reduced the sample to 23230. Removing the 3127 (13.5\%) people for whom BMI data were missing resulted in a final sample for analysis of 20103 individuals.

The unweighted sample included 422 nurses $(2.1 \%)$, 412 other healthcare professionals (2.0\%), 736 unregistered care workers (3.7\%) and $18533(92.2 \%)$ people in non-health-related occupations (table 2).

\section{Obesity prevalence}

After weighting of data, prevalence of obesity (BMI $\geq 30$ ) among nurses was $25.12 \%$ (95\% CI $20.88 \%$ to $29.37 \%$ ) (table 3). Prevalence of obesity was higher among nurses than other healthcare professionals $(14.39 \%, 95 \%$ CI $11.00 \%$ to $17.77 \%$ ) and people in non-health-related occupations $(23.51 \%, 95 \%$ CI $22.92 \%$ to $24.10 \%)$ but lower than among unregistered care workers, who had the highest prevalence among healthcare professionals (31.88\%, 95\% CI $28.44 \%$ to $35.32 \%)$. A similar pattern was observed for being overweight (BMI $\geq 25$ ) (table 3).

A logistic regression model adjusted for age, sex and survey year indicated that, compared with nurses, the odds of being obese were significantly lower for other healthcare professionals (adjusted OR (aOR) 0.52, 95\% CI 0.37 to 0.75 ) but higher for unregistered care workers (aOR $1.46,95 \%$ CI 1.11 to 1.93 ) (table 4 ). No statistically significant difference was observed in prevalence of obesity between nurses and people working in non-health-related occupations (aOR 0.94 CI, 0.74, 1.18).

\section{DISCUSSION}

A quarter of nurses in England were obese (25.1\%). Prevalence of obesity was lower compared with nurses in Australia $(28.5 \%),{ }^{15} \mathrm{New}$ Zealand $(28.2 \%),{ }^{15}$ the 
Table 2 Sample sociodemographic characteristics

\begin{tabular}{|c|c|c|c|c|c|c|c|c|c|c|}
\hline & \multicolumn{2}{|c|}{ Nurses $(n=422)$} & \multicolumn{2}{|c|}{$\begin{array}{l}\text { Other healthcare } \\
\text { professionals }(n=412)\end{array}$} & \multicolumn{2}{|c|}{$\begin{array}{l}\text { Unregistered care } \\
\text { workers }(n=736)\end{array}$} & \multicolumn{2}{|c|}{$\begin{array}{l}\text { Non-health-related } \\
\text { occupations } \\
(n=18533)\end{array}$} & \multicolumn{2}{|c|}{ Total $(n=20103)$} \\
\hline & $\mathbf{n}$ & $\%$ & $\mathbf{n}$ & $\%$ & $\mathbf{n}$ & $\%$ & $\mathbf{n}$ & $\%$ & $\mathbf{n}$ & $\%$ \\
\hline \multicolumn{11}{|l|}{ Survey } \\
\hline 2008 & 147 & 34.83 & 129 & 31.31 & 231 & 31.39 & 6526 & 35.21 & 7033 & 34.98 \\
\hline 2009 & 41 & 9.72 & 38 & 9.22 & 59 & 8.02 & 1971 & 10.64 & 2109 & 10.49 \\
\hline 2011 & 79 & 18.72 & 79 & 19.17 & 157 & 21.33 & 3450 & 18.62 & 3765 & 18.73 \\
\hline 2012 & 68 & 16.11 & 73 & 17.72 & 144 & 19.57 & 3250 & 17.54 & 3535 & 17.58 \\
\hline \multicolumn{11}{|l|}{ Gender } \\
\hline Male & 47 & 11.14 & 109 & 26.46 & 94 & 12.77 & 9660 & 52.12 & 9910 & 49.30 \\
\hline $30-34$ & 38 & 9 & 54 & 13.11 & 78 & 10.6 & 2056 & 11.09 & 2226 & 11.07 \\
\hline $35-39$ & 56 & 13.27 & 53 & 12.86 & 74 & 10.05 & 2296 & 12.39 & 2479 & 12.33 \\
\hline $40-44$ & 72 & 17.06 & 62 & 15.05 & 101 & 13.72 & 2727 & 14.71 & 2962 & 14.73 \\
\hline $45-49$ & 90 & 21.33 & 64 & 15.53 & 107 & 14.54 & 2553 & 13.78 & 2814 & 14.00 \\
\hline $50-54$ & 55 & 13.03 & 48 & 11.65 & 96 & 13.04 & 2230 & 12.03 & 2429 & 12.08 \\
\hline $55-59$ & 47 & 11.14 & 41 & 9.95 & 82 & 11.14 & 1916 & 10.34 & 2086 & 10.38 \\
\hline$\geq 60$ & 18 & 4.27 & 19 & 4.61 & 70 & 9.51 & 1456 & 7.86 & 1563 & 7.77 \\
\hline \multicolumn{11}{|l|}{ BMI } \\
\hline $\begin{array}{l}\text { Mean } \\
\text { (SD) }\end{array}$ & 27.26 & (5.20) & 25.91 & $(4.71)$ & 28.35 & $(6.23)$ & 27.19 & $(5.03)$ & 27.21 & (5.08) \\
\hline
\end{tabular}

*Underweight included with normal weight due to small numbers.

BMI, body mass index.

USA $(27.0 \%),{ }^{37}$ South Africa $(51.6 \%)^{38}$ and Scotland $(29.4 \%)^{11}$

Obesity prevalence was especially high among older nurses. As almost half (47.1\%) of English nurses are over the age of 45 years, ${ }^{39}$ this poses a likely future burden of ill health for the healthcare workforce. Prevalence of obesity among nurses was statistically significantly higher than among other healthcare professionals such as allied health professionals who, although categorised in the same socioeconomic classification, are less likely to work shifts and have disruptive working patterns that contribute to obesity. Prevalence of obesity among nurses

Table 3 Obesity and overweight by occupational group

\begin{tabular}{|c|c|c|c|c|c|c|}
\hline \multirow{3}{*}{ Occupational group } & \multicolumn{3}{|c|}{ Obese (BMI $\geq 30.00)$} & \multicolumn{3}{|c|}{ Overweight (BMI $\geq 25.00)$} \\
\hline & \multicolumn{3}{|c|}{ Weighted } & \multicolumn{3}{|c|}{ Weighted } \\
\hline & $\%$ & $95 \% \mathrm{Cl}$ & & $\%$ & $95 \% \mathrm{Cl}$ & \\
\hline Nurses & 25.12 & 20.88 & 29.37 & 60.79 & 56.02 & 65.57 \\
\hline Other healthcare professionals & 14.39 & 11.00 & 17.77 & 49.00 & 44.18 & 53.82 \\
\hline Non-health-related occupations & 23.51 & 22.92 & 24.10 & 62.54 & 61.86 & 63.21 \\
\hline
\end{tabular}


Table 4 Binary logistic regression models

\begin{tabular}{|c|c|c|c|c|}
\hline & \multicolumn{4}{|l|}{$\begin{array}{l}\text { Obese (BMI } \geq 30.00) \\
\text { Unweighted }\end{array}$} \\
\hline & \multicolumn{2}{|c|}{ Unweighted } & \multicolumn{2}{|c|}{ Weighted } \\
\hline & Unadjusted & Adjusted & Unadjusted & Adjusted \\
\hline \multicolumn{5}{|l|}{ Occupational groups } \\
\hline Nurse & Comparison & Comparison & Comparison & Comparison \\
\hline Other healthcare professionals & $0.53(0.37 \text { to } 0.75)^{\star}$ & $0.55(0.39 \text { to } 0.77)^{\star}$ & $0.50(0.35 \text { to } 0.72)^{*}$ & $0.52(0.37 \text { to } 0.75)^{*}$ \\
\hline Unregistered care staff & $1.34(1.02 \text { to } 1.75)^{\star}$ & $1.40(1.07 \text { to } 1.83)^{\star}$ & $1.40(1.06 \text { to } 1.84)^{\star}$ & $1.46(1.11 \text { to } 1.93)^{\star}$ \\
\hline Non-health-related occupations & 0.91 (0.73 to 1.13$)$ & $0.92(0.73$ to 1.15$)$ & $0.92(0.73$ to 1.15$)$ & 0.94 (0.74 to 1.18$)$ \\
\hline \multicolumn{5}{|l|}{ Survey year } \\
\hline 2008 & Comparison & Comparison & Comparison & Comparison \\
\hline 2009 & $0.96(0.85$ to 1.07$)$ & $0.95(0.85$ to 1.07$)$ & 0.91 (0.81 to 1.02$)$ & 0.91 (0.81 to 1.02$)$ \\
\hline 2010 & $1.11(1.01 \text { to } 1.22)^{*}$ & $1.10(1.00$ to 1.20$)$ & $1.11(1.02 \text { to } 1.21)^{\star}$ & $1.10(1.01 \text { to } 1.21)^{*}$ \\
\hline 2011 & 0.97 (0.88 to 1.07$)$ & $0.96(0.88$ to 1.06$)$ & 0.95 (0.86 to 1.04$)$ & 0.93 (0.85 to 1.02$)$ \\
\hline 2012 & 0.95 (0.87 to 1.05$)$ & 0.94 (0.85 to 1.03$)$ & $0.96(0.87$ to 1.05$)$ & 0.94 (0.86 to 1.03$)$ \\
\hline \multicolumn{5}{|l|}{ Gender } \\
\hline Male & Comparison & Comparison & Comparison & Comparison \\
\hline Female & $0.92(0.86 \text { to } 0.98)^{*}$ & $1.21(1.05 \text { to } 1.39)^{\star}$ & $0.93(0.87 \text { to } 0.99)^{*}$ & $0.90(0.84 \text { to } 0.96)^{\star}$ \\
\hline \multicolumn{5}{|l|}{ Age (years) } \\
\hline$\leq 29$ & Comparison & Comparison & Comparison & Comparison \\
\hline $30-34$ & $1.21(1.05 \text { to } 1.39)^{*}$ & $1.21(1.05 \text { to } 1.39)^{\star}$ & $1.26(1.10 \text { to } 1.43)^{\star}$ & $1.26(1.10 \text { to } 1.43)^{*}$ \\
\hline $35-39$ & $1.65(1.45 \text { to } 1.88)^{\star}$ & $1.66(1.45 \text { to } 1.89)^{\star}$ & $1.78(1.57 \text { to } 2.01)^{\star}$ & $1.78(1.58 \text { to } 2.02)^{\star}$ \\
\hline $40-44$ & $1.74(1.54 \text { to } 1.97)^{\star}$ & $1.74(1.54 \text { to } 1.97)^{\star}$ & $1.83(1.63 \text { to } 2.05)^{*}$ & $1.83(1.63 \text { to } 2.05)^{\star}$ \\
\hline $45-49$ & $2.10(1.86 \text { to } 2.38)^{*}$ & $2.11(1.87 \text { to } 2.39)^{\star}$ & $2.30(2.04 \text { to } 2.58)^{\star}$ & $2.30(2.05 \text { to } 2.59)^{\star}$ \\
\hline $50-54$ & $2.32(2.04 \text { to } 2.63)^{\star}$ & $2.32(2.04 \text { to } 2.63)^{*}$ & $2.54(2.26 \text { to } 2.86)^{*}$ & $2.54(2.25 \text { to } 2.86)^{\star}$ \\
\hline $55-59$ & $2.43(2.14 \text { to } 2.77)^{\star}$ & $2.43(2.13 \text { to } 2.77)^{\star}$ & $2.55(2.24 \text { to } 2.89)^{\star}$ & 2.55 (2.25 to 2.90$)^{*}$ \\
\hline$\geq 60$ & $2.21(1.92 \text { to } 2.55)^{\star}$ & $2.18(1.89 \text { to } 2.51)^{*}$ & $2.33(2.02 \text { to } 2.68)^{\star}$ & $2.31(2.00 \text { to } 2.66)^{\star}$ \\
\hline
\end{tabular}

${ }^{*} \mathrm{P}<0.05$.

BMI, body mass index.

was significantly lower than in unregistered care workers. This reflects population-level inequalities in obesity prevalence, where obesity is more common in people with low educational attainment, low income or in manual occupations. ${ }^{40-42}$

There was no statistically significant difference between the prevalence of obesity among nurses and the general working population. The greater health literacy of nurses might be expected to contribute to lower rates of obesity than the general population, but this study has shown that nurses are no more able to maintain a healthy weight than their age-related and gender-related cohorts.

\section{Implications for policy and practice}

These findings on the prevalence of obesity have important implications for the health of the health and social care workforce, the effectiveness of health promotion delivered by healthcare professionals and patient safety. Given the established link between obesity and increased risk of illness and injury, obesity among healthcare professionals potentially harms their health. Obese individuals may struggle with health issues associated with obesity, including fatigue, breathlessness or arthritis, that could reduce productivity in the workplace. ${ }^{43}$ Workforce capacity may be reduced through increased absenteeism and premature workforce exit. ${ }^{44}$ Together these two factors could increase the cost of service delivery considerably through sickness absence payments for existing staff, increased salary costs of temporary (agency) staff, increased training costs to replace staff and the attendant loss of experience and expertise. The high prevalence of obesity among the healthcare workforce should urge policymakers and employers to provide solutions, such as supporting staff to maintain a healthy weight through workplace initiatives. ${ }^{45}$ Investment in staff health would in turn benefit the health service in terms of sustainability and high-quality patient care via positive impacts on productivity, retention and absence rates through improved morale, job satisfaction and well-being. ${ }^{47}$

Obesity among healthcare professionals may hinder effective patient care through performance impairments 
that impact on patient safety. Nurses who are obese may experience considerable difficulty in carrying out certain physical aspects of patient care activities requiring access to tight spaces, range of motion and mobility and may struggle to perform nursing tasks such as cardiopulmonary resuscitation, moving and handling and attending to patients' personal care needs due to limited space in washrooms. ${ }^{48}$ Even physically fit nurses are at risk of workplace injury, and performing certain physical aspects of the nursing role while obese may further harm nurses' health or increase the likelihood of injury, potentially leading to sickness absence or workforce exit. More research is required to assess the impact of obesity on nurses' ability to physically and mentally perform their role.

This research has important implications for approaches to service design and workforce realignment, especially in the context of expanded roles for unregistered care workers in England ${ }^{49}$ who were found to have the highest prevalence of overweight and obesity in our study. Urgent action from NHS England, involving occupational health $(\mathrm{OH})$ and human resources $(\mathrm{HR})$ departments across Trusts, is required to "put its own house in order' and reduce the prevalence of obesity among healthcare professionals that was found to be higher than published Department of Health estimates. ${ }^{50}$ Only through such concerted effort will the health service in England prevent the potentially harmful effects that high levels of obesity may have on patient care, the sustainability of the health service and-most importantly-the individual health of those who work within it.

\section{Strengths and limitations}

This is the first study to use the HSE to estimate prevalence of obesity among healthcare professionals. Data were drawn from a nationally representative sample of the English population, which enhances generalisability. The height and weight measurements used to derive BMI were taken by trained interviewers rather than self-reported, which increases reliability. However, the study does have several limitations. First, BMI data for some participants $(13.5 \%)$ were missing, although there was no statistically significant difference in the extent of missing data between occupational groups $(\mathrm{P}=0.86)$. Second, heterogeneity of roles and fields of practice within the nursing workforce is masked by the inability to differentiate within the single occupational classification of nurses. Third, there was no question about parental socioeconomic status that might have enabled analysis of social mobility in contrast to work done elsewhere on nurses and weight that drew on the Scottish Health Survey. ${ }^{11}$ Fourth, ethnicity might also partially account for the high rates of obesity: obesity rates are $9 \%$ higher in black women relative to white women and nearly $10 \%$ of the qualified nursing workforce identifies as black or black British, ${ }^{39}$ but the numbers included in the HSE were too small for confident analysis and to protect anonymity. Finally, for similar reasons, it was not possible to investigate the responses of individuals to questions asked in the HSE about weight perceptions and intentions to lose weight and their measured BMI. ${ }^{51}$

\section{CONCLUSIONS}

A quarter of nurses in England were obese (BMI $\geq 30$ ). Prevalence of obesity among nurses was statistically significantly higher than other healthcare professionals, but significantly lower than unregistered care workers. There was no statistically significant difference between levels of obesity among nurses and the general working population. Obesity among healthcare professionals has potentially negative implications for the capacity, efficacy, sustainability and safety of healthcare services and the health of healthcare professionals. Further research is required to better understand the reasons for high levels of obesity among healthcare professionals, especially nurses and unregistered care workers. Urgent action is required to support healthcare professionals to achieve and maintain a healthy weight.

Contributors RGK, IA and JW designed the study. IA conducted data analysis. RGK wrote the first draft of the manuscript, and IA, JW, CM, LH and MK revised the manuscript for important intellectual content. All authors approved the final version.

Funding Study undertaken as part of the Win. project (the Healthy Weight Initiative for Nurses) funded by Burdett Trust for Nursing, the Royal College of Nursing and the Royal College of Nursing Foundation in collaboration with C3 Collaborating for Health. The funder had no involvement in study design, data analysis or interpretation, and drafting or revising the manuscript.

Competing interests None declared.

Ethics approval The study was reviewed and approved by the Research Ethics Committee at London South Bank University (UREC 1616) and the Research Integrity Committee in the School of Health \& Social Care at Edinburgh Napier University (FHLSS/1664).

Provenance and peer review Not commissioned; externally peer reviewed.

Data sharing statement Health Survey for England data are available from NatCen Social Research.

Open Access This is an Open Access article distributed in accordance with the Creative Commons Attribution Non Commercial (CC BY-NC 4.0) license, which permits others to distribute, remix, adapt, build upon this work non-commercially, and license their derivative works on different terms, provided the original work is properly cited and the use is non-commercial. See: http://creativecommons.org/ licenses/by-nc/4.0/

(c) Article author(s) (or their employer(s) unless otherwise stated in the text of the article) 2017. All rights reserved. No commercial use is permitted unless otherwise expressly granted.

\section{REFERENCES}

1. Logue J, Murray HM, Welsh P, et al. Obesity is associated with fatal coronary heart disease independently of traditional risk factors and deprivation. Heart 2011;97:564-8.

2. Renehan AG, Tyson M, Egger M, et al. Body-mass index and incidence of cancer: a systematic review and meta-analysis of prospective observational studies. Lancet 2008;371:569-78.

3. Bell JA, Kivimaki M, Hamer M. Metabolically healthy obesity and risk of incident type 2 diabetes: a meta-analysis of prospective cohort studies. Obes Rev 2014;15:504-15.

4. Reed LF, Battistutta D, Young J, et al. Prevalence and risk factors for foot and ankle musculoskeletal disorders experienced by nurses. BMC Musculoskelet Disord 2014;15:196.

5. Wang YC, McPherson K, Marsh T, et al. Health and economic burden of the projected obesity trends in the USA and the UK. Lancet 2011;378:815-25. 
6. Dobbs R, Sawers C, Thompson F, et al. Overcoming obesity: an initial economic analysis. 2014

7. $\mathrm{Ng} \mathrm{M}$, Fleming T, Robinson M, et al. Global, regional, and national prevalence of overweight and obesity in children and adults during 1980-2013: a systematic analysis for the global burden of disease study 2013. Lancet 2014;384:766-81.

8. Moody A, Neave A. Health survey for England 2015. Adult overweight and obesity. London, 2016. http://www.content.digital.nhs.uk/ catalogue/PUB22610/HSE2015-Adult-obe.pdf

9. Butland B, Jebb S, Kopelman P, et al. Foresight. Tackling obesities: future choices project report. London, UK, 2007.

10. Department of Health. Healthy weight, healthy lives: one year on. London, 2009.

11. Kyle RG, Neall RA, Atherton IM. Prevalence of overweight and obesity among nurses in Scotland: a cross-sectional study using the scottish health survey. Int J Nurs Stud 2016;53:126-33.

12. Studnek JR, Bentley M, Crawford JM, et al. An assessment of key health indicators among emergency medical services professionals. Prehosp Emerg Care 2010;14:14-20.

13. Holman GT, Thomas RE, Brown KC. A health comparison of Alabama nurses versus US, UK, and Canadian normative populations. $J$ Orthop Nurs 2009;13:172-82.

14. Zapka JM, Lemon SC, Magner RP, et al. Lifestyle behaviours and weight among hospital-based nurses. J Nurs Manag 2009;17:853-60.

15. Bogossian FE, Hepworth J, Leong GM, et al. A cross-sectional analysis of patterns of obesity in a cohort of working nurses and midwives in Australia, New Zealand, and the United Kingdom. Int J Nurs Stud 2012;49:727-38.

16. Anandacoomarasamy A, Caterson I, Sambrook P, et al. The impact of obesity on the musculoskeletal system. Int J Obes 2008;32:211-22.

17. Luppino FS, de Wit LM, Bouvy PF, et al. Overweight, obesity, and depression. Arch Gen Psychiatry 2010;67:220.

18. Mather AA, Cox BJ, Enns MW, et al. Associations of obesity with psychiatric disorders and suicidal behaviors in a nationally representative sample. J Psychosom Res 2009;66:277-85.

19. Health and Safety Executive. Labour force survey - self-reported work-related ill health and workplace injuries. Labour force survey. 2016 http://www.hse.gov.uk/statistics/lfs/index.htm (accessed 8 Aug 2017).

20. Nicholls R, Perry L, Duffield C, et al. Barriers and facilitators to healthy eating for nurses in the workplace: an integrative review. $J$ Adv Nurs 2017;73:1051-65.

21. Peplonska B, Bukowska A, Sobala W. Association of rotating night shift work with BMI and abdominal obesity among nurses and midwives. PLoS One 2015;10:e0133761-13.

22. Wong $\mathrm{H}$, Wong $\mathrm{MC}$, Wong SY, et al. The association between shift duty and abnormal eating behavior among nurses working in a major hospital: a cross-sectional study. Int J Nurs Stud 2010;47:1021-7.

23. Amani R, Gill T. Shiftworking, nutrition and obesity: implications for workforce health- a systematic review. Asia Pac J Clin Nutr 2013;22:505-15.

24. Schulte PA, Wagner GR, Ostry A, et al. Work, obesity, and occupational safety and health. Am J Public Health 2007;97:428-36.

25. Fujishiro K, Lawson CC, Hibert EL, et al. Job strain and changes in the body mass index among working women: a prospective study. Int J Obes 2015;39:1395-400.

26. Health and Social Care Information Centre. NHS Workforce Statistics 9 April 2016, Provisional statistics [Internet. NHS Workforce Statistics, 2016. http://www.hscic.gov.uk/catalogue/PUB21066/nhswork-stat-apr-2016-pdf.pdf

27. World Health Organisation. The 2014 update, Global health workforce statistics. Geneva, Switzerland, 2014. http://apps.who.int/gho/data/ node. main?showonly=HWF

28. Marshall LC. Teachable moments. Nurs manage 2016.

29. NHS England. NHS Standard contract $2017 / 18$ and 2018/19 service conditions. London, UK, 2016. https://www.england.nhs.uk/wpcontent/uploads/2016/11/2-service-conditions-fl.pdf

30. Curtice J. Attitudes to obesity. Findings from the 2015 British social attitudes survey. London, UK, 2016. http://www.bsa.natcen.ac.uk/ media/39132/attitudes-to-obesity.pdf
31. Kelly M, Wills J, Jester R, et al. Should nurses be role models for healthy lifestyles? Results from a modified Delphi study. J Adv Nurs 2017;73:665-78.

32. Kelly M, Sykes S, Wills J. Do healthcare professionals' own health behaviours impact on patient outcomes? A systematic review 2017.

33. Fie S, Norman IJ, While AE. The relationship between physicians' and nurses' personal physical activity habits and their healthpromotion practice: a systematic review. Health Educ $J$ 2013;72:102-19.

34. Lobelo F, de Quevedo IG. The evidence in support of physicians and health care providers as physical activity role models Am J Lifestyle Med. 2016;10:36-52 http://search.ebscohost.com/login.aspx? direct=true\&db=cmedm\&AN=26213523\&site=ehost-live (Global Health Promotion Office, National Center for Chronic Disease Prevention and Health Promotion, Centers for Disease Control and Prevention).

35. NatCen social research and UCL. Health Survey for England 2012: User Guide. London: NatCen Social Research, 2012. http://doc. ukdataservice.ac.uk/doc/7480/mrdoc/pdf/7480userguide.pdf. (accessed Aug 11 2017)

36. Rose D, Pevalin D, O'Reilly K. The National statistics socio-economic classification: origins, development and use. Basingstoke, UK: Palgrave Macmillan, 2005

37. Zitkus BS. The relationship among registered nurses' weight status, weight loss regimens, and successful or unsuccessful weight loss. J Am Acad Nurse Pract 2011;23:110-6.

38. Goon D, Maputle M, Olukoga A, et al. Overweight, obesity and underweight in nurses in Vhembe and Capricorn districts, Limpopo. South African Journal of Clinical Nutrition 2013;26:147-9.

39. NHS Digital. HCHS staff in NHS trusts and CCGs in England, equality and diversity tables. $2016 \mathrm{https} / / /$ digital.nhs.uk/article/2021/WebsiteSearch? productid $=21281$.

40. Loring B, Robertson A. Obesity and inequities: guidance for addressing inequities in overweight and obesity. Copenhagen, 2014. http://www.euro.who.int/_data/assets/pdf_file/0003/247638/ obesity-090514.pdf

41. Swinburn BA, Sacks G, Hall KD, et al. The global obesity pandemic: shaped by global drivers and local environments. Lancet 2011;378:804-14.

42. Moody A, Neave A. Health Survey for England 2015. Adult overweight and obesity. London, UK, 2016. http://content.digital.nhs. uk/catalogue/PUB22610/HSE2015-Adult-obe.pdf

43. Finkelstein EA, Linnan LA, Tate DF, et al. A longitudinal study on the relationship between weight loss, medical expenditures, and absenteeism among overweight employees in the way to health study. J Occup Environ Med 2009;51:1367-73.

44. Kouwenhoven-Pasmooij TA, Burdorf A, Roos-Hesselink JW, et al. Cardiovascular disease, diabetes and early exit from paid employment in Europe; the impact of work-related factors. Int J Cardiol 2016;215:332-7.

45. Stevens S. Get serious about obesity or bankrupt the NHS. NHS England, 2014. https://www.england.nhs.uk/2014/09/serious-aboutobesity/

46. NHS England, Care Quality Commission, Health Education England, Monitor,Public Health England, Trust Development Authority. NHS five year forward view. London, 2014. http://www.england.nhs.uk/ ourwork/futurenhs/.

47. The Royal College of Physicians. Work and wellbeing in the NHS: why staff health matters to patient care Setting higher standards. London, UK, 2015.

48. Krussig K, Willoughby D, Parker V, et al. Obesity among nurses: prevalence and impact on work. Am J Nurse Pract 2012;8:14-21.

49. Health Education England. Nursing Associate - a new support role for nursing. http://tinyurl.com/zqbmeko (accessed 6 Jun 2017).

50. Cross-Government Obesity Unit. Healthy weight, healthy lives: One year on. London, UK, 2009.

51. Robinson E, Oldham M. Weight status misperceptions among UK adults: the use of self-reported vs. measured BMI. BMC Obes 2016;3. 